\title{
MENGHITUNG DETERMINAN MATRIKS BLOK MENGGUNAKAN EKSPANSI LAPLACE DAN KOMPLEMEN SCHUR
}

\author{
WULAN PURNAMA SARI, NOVA NOLIZA BAKAR, YANITA \\ Program Studi S1 Matematika, \\ Fakultas Matematika dan Ilmu Pengetahuan Alam, Universitas Andalas, \\ Kampus UNAND Limau Manis Padang, Indonesia. \\ email : wps4318@gmail.com,novanoliza@sci.unand.ac.id,yanita@sci.unand.ac.id
}

Diterima 17 Februari 2020 Direvisi 7 Maret 2020 Dipublikasikan 29 April 2020

\begin{abstract}
Abstrak. Penelitian ini membahas tentang perhitungan determinan suatu matriks yang telah diblok. Perhitungan determinan ini menggunakan dua metode yaitu metode Ekspansi Laplace dan metode Komplemen Schur. Pada metode Komplemen Schur akan dilakukan generalisasi pada matriks blok untuk menghitung determinannya.
\end{abstract}

Kata Kunci: Determinan, Matriks Blok, Ekspansi Laplace, Komplemen Schur

\section{Pendahuluan}

Pada teori matriks, perhitungan determinan merupakan salah satu kajian yang sering dibahas. Perhitungan determinan terkait dengan matriks berukuran kecil $(n \leq 3)$ biasanya tidak pernah menjadi masalah, hanya dengan menggunakan definisi determinan biasanya langsung dapat diselesaikan. Namun perhitungan determinan matriks dengan ukuran yang besar, sukar dilakukan jika hanya menggunakan definisi determinan.

Beberapa metode yang dapat digunakan untuk menghitung determinan matriks adalah metode reduksi baris, metode ekspansi Laplace/kofaktor dan metode komplemen Schur. Metode lain yang dapat digunakan adalah dengan mengubah matriks tersebut menjadi matriks blok. Untuk menentukan determinan matriks blok tersebut, pada penelitian ini akan digunakan dua metode yaitu metode ekspansi Laplace/kofaktor dan metode komplemen Schur. [4]

\section{Landasan Teori}

\subsection{Matriks dan Operasi Matriks}

Definisi 2.1. [3] Misalkan $M$ sebagai matriks bujur sangkar berukuran $b \times b$. Matriks $M$ disebut matriks segitiga atas jika $m_{i j}=0$ untuk $i>j$, dan $M$ dikatakan

${ }^{*}$ penulis korespondensi 
matriks segitiga bawah jika $m_{i j}=0$ untuk $i<j$.

Definisi 2.2. [5] Misalkan $M$ dan $N$ adalah matriks bujur sangkar berukuran sama. Jika $M N=N M=I$, maka $M$ dikatakan invertible (dapat dibalik) dan $N$ disebut invers dari $M$ yang disimbolkan dengan $M^{-1}$.

Definisi 2.3. [1] Sebuah matriks bujur sangkar M yang mempunyai sifat

$$
M^{-1}=M^{T}
$$

disebut matriks ortogonal.

Definisi 2.4. [2] Matriks $M$ dan $N$ disebut matriks bolak balik atau komutatif jika $M N=N M$.

Definisi 2.5. [1] Matriks blok atau matriks partisi adalah matriks yang dipartisi atau diblok menjadi beberapa matriks yang ukurannya lebih kecil dengan memasukkan garis horizontal dan garis vertikal antara baris dan kolom matriks. Matriksmatriks kecil hasil partisi disebut submatriks.

Definisi 2.6. [4] Suatu matriks blok $M=\left[\begin{array}{cccc}A_{11} & A_{12} & \cdots & A_{1 k} \\ A_{21} & A_{22} & \cdots & A_{2 k} \\ \vdots & \vdots & \ddots & \vdots \\ A_{k 1} & A_{k 2} & \cdots & A_{k k}\end{array}\right]$ dikatakan komutatif berpasangan jika dan hanya jika $A_{i j} A_{l m}=A_{l m} A_{i j}$ untuk setiap pasangan indeks.

\subsection{Determinan Matriks}

Definisi 2.7. [3] Misalkan $M=\left[m_{i j}\right]$ adalah matriks berukuran $n \times n$. Fungsi determinan dari $M$ disimbolkan dengan $\operatorname{det}(M)$ atau $|M|$ yang didefinisikan sebagai berikut:

$$
\operatorname{det}(M)=|M|=\sum_{\sigma \in S_{n}} s g(\sigma) m_{1 \sigma_{1}} m_{2 \sigma_{2}} \cdots m_{n \sigma_{n}} .
$$

Teorema 2.8. [1] Jika $M$ dan $N$ adalah matriks bujur sangkar yang berukuran sama, maka

$$
\operatorname{det}(M N)=\operatorname{det}(M) \operatorname{det}(N) .
$$

Teorema 2.9. [3] Untuk setiap matriks $M$ berukuran $n \times n$ dengan $1 \leq i, j \leq n$ berlaku:

$$
\begin{gathered}
\operatorname{det}(M)=|M|=\sum_{j=1}^{n} m_{i j} C_{i j}=\sum_{j=1}^{n} m_{i j}(-1)^{i+j} \operatorname{det}(M(i \mid j)) \\
\quad \text { ekspansi kofaktor } / \text { Laplace sepanjang baris } i . \\
\operatorname{det}(M)=|M|=\sum_{i=1}^{n} m_{i j} C_{i j}=\sum_{i=1}^{n} m_{i j}(-1)^{i+j} \operatorname{det}(M(i \mid j)) \\
\text { ekspansi kofaktor/Laplace sepanjang kolom } j .
\end{gathered}
$$

Teorema 2.10. [1] Jika M adalah matriks segitiga berukuran $n \times n$ (segitiga bawah dan segitiga atas) maka $\operatorname{det}(M)$ adalah hasil kali dari entri pada diagonal utama matriks, yaitu

$$
\operatorname{det}(M)=m_{11} m_{22} \cdots m_{n n}
$$


140 Wulan Purnama Sari dkk

\subsection{Induksi Matematika}

Salah satu metode yang dapat digunakan dalam pembuktian suatu pernyataan matematika adalah induksi matematika. Induksi matematika terdiri dari dua langkah, yaitu:

(i) langkah basis: tunjukkan bahwa $P(1)$ benar.

Langkah basis tidak selalu ditunjukkan bahwa $P(1)$ benar. Jika suatu pernyataan $P(n)$ tidak bisa ditunjukkan bahwa $P(1)$ benar maka tunjukkan bahwa $P(2)$ benar, begitu seterusnya.

(ii) langkah induktif: tunjukkan bahwa jika $P(k)$ benar maka $P(k+1)$ juga benar untuk suatu bilangan positif $k$.

Untuk menyelesaikan langkah induktif pada induksi matematika, asumsikan bahwa $P(k)$ benar untuk bilangan bulat positif $k$ dan tunjukkan bahwa $P(k+1)$ juga benar. [6]

\subsection{Faktorisasi $Q R$}

Misalkan $M$ adalah matriks berukuran $a \times b$ yang kolom-kolomnya bebas linier. Suatu faktorisasi $Q R$ pada $M$ adalah suatu faktorisasi yang menjadikan $M=Q R$, dimana $Q$ adalah matriks $a \times b$ yang memiliki kolom-kolom orthonormal dan $R$ adalah matriks segitiga atas berukuran $b \times b$ yang invertible.

\section{Pembahasan}

\subsection{Ekspansi Laplace}

Proposisi 3.1. [4] Misalkan $M=\left[\begin{array}{c|c}A & B \\ \hline O & D\end{array}\right]$ adalah matriks blok dimana $A$ adalah matriks $m \times m$ dengan vektor-vektor kolom pada $A$ bebas linier, $D$ adalah matriks $n \times n$ dengan vektor-vektor kolom pada $D$ bebas linier, dan $O$ adalah $n \times m$ matriks nol, maka

$$
\operatorname{det}(M)=\operatorname{det}(A) \operatorname{det}(D)
$$

Bukti. Pertama asumsikan matriks $B$ adalah matriks nol. Perhatikan bahwa

$$
\left[\begin{array}{ll}
A & O \\
O & D
\end{array}\right]=\left[\begin{array}{ll}
A & O \\
O & I_{n}
\end{array}\right]\left[\begin{array}{cc}
I_{m} & O \\
O & D
\end{array}\right]
$$

dimana $I_{n}$ dan $I_{m}$ adalah matriks identitas berukuran $n \times n$ dan $m \times m$. Berdasarkan Teorema 2.8 maka berlaku:

$$
\operatorname{det}\left(\left[\begin{array}{ll}
A & O \\
O & D
\end{array}\right]\right)=\operatorname{det}\left(\left[\begin{array}{ll}
A & O \\
O & I_{n}
\end{array}\right]\right) \operatorname{det}\left(\left[\begin{array}{cc}
I_{m} & O \\
O & D
\end{array}\right]\right) .
$$

(a) Akan ditunjukkan $\operatorname{det}\left(\left[\begin{array}{ll}A & O \\ O & I_{n}\end{array}\right]\right)=\operatorname{det}(A)$. 
(b) Akan ditunjukkan $\operatorname{det}\left(\left[\begin{array}{cc}I_{m} & O \\ O & D\end{array}\right]\right)=\operatorname{det}(D)$. Dengan demikian diperoleh

$$
\begin{gathered}
\operatorname{det}\left[\begin{array}{ll}
A & O \\
O & D
\end{array}\right]=\operatorname{det}\left[\begin{array}{ll}
A & O \\
O & I_{n}
\end{array}\right] \operatorname{det}\left[\begin{array}{cc}
I_{m} & O \\
O & D
\end{array}\right] \\
=\operatorname{det}(A) \operatorname{det}(D) .
\end{gathered}
$$

Selanjutnya akan ditunjukkan untuk $B$ bukan matriks nol. Karena $A$ dan $D$ merupakan matriks kuadrat maka berdasarkan Definisi Faktorisasi $Q R$

$$
M=\left[\begin{array}{cc}
A & B \\
O & D
\end{array}\right]=\left[\begin{array}{cc}
Q_{A} R_{A} & B \\
O & Q_{D} R_{D}
\end{array}\right]=\left[\begin{array}{cc}
Q_{A} & O \\
O & Q_{D}
\end{array}\right]\left[\begin{array}{cc}
R_{A} & Q_{A}^{T} B \\
O & R_{D}
\end{array}\right] .
$$

Berdasarkan Persamaan (3.1) diperoleh

$$
\operatorname{det}\left[\begin{array}{cc}
Q_{A} & O \\
O & Q_{D}
\end{array}\right]=\operatorname{det}\left(Q_{A}\right) \operatorname{det}\left(Q_{D}\right)
$$

Karena $R_{A}$ dan $R_{D}$ merupakan matriks segitiga atas dan $\left[\begin{array}{cc}R_{A} & Q_{A}^{T} B \\ O & R_{D}\end{array}\right]$ juga merupakan matriks segitiga atas, sehingga berdasarkan Teorema 2.10 berlaku:

$$
\operatorname{det}\left[\begin{array}{cc}
R_{A} & Q_{A}^{T} B \\
O & R_{D}
\end{array}\right]=\operatorname{det}\left(R_{A}\right) \operatorname{det}\left(R_{D}\right) .
$$

Dari Persamaan (3.2) dan (3.3) diperoleh

$$
\begin{aligned}
\operatorname{det}(M) & =\operatorname{det}\left(\left[\begin{array}{ll}
A & B \\
O & D
\end{array}\right]\right) \\
& =\operatorname{det}\left(\left[\begin{array}{cc}
Q_{A} & O \\
O & Q_{D}
\end{array}\right]\right) \operatorname{det}\left(\left[\begin{array}{cc}
R_{A} & Q_{A}^{T} B \\
O & R_{D}
\end{array}\right]\right) \\
& =\left(\operatorname{det}\left(Q_{A}\right) \operatorname{det}\left(Q_{D}\right)\right)\left(\operatorname{det}\left(R_{A}\right) \operatorname{det}\left(R_{D}\right)\right) \\
& =\left(\operatorname{det}\left(Q_{A}\right) \operatorname{det}\left(R_{A}\right)\right)\left(\operatorname{det}\left(Q_{D}\right) \operatorname{det}\left(R_{D}\right)\right) \\
& =\operatorname{det}\left(Q_{A} R_{A}\right) \operatorname{det}\left(Q_{D} R_{D}\right) \\
& =\operatorname{det}(A) \operatorname{det}(D) .
\end{aligned}
$$

Dengan demikian terbukti bahwa $\operatorname{det}(M)=\operatorname{det}(A) \operatorname{det}(D)$.

\subsection{Komplemen Schur}

Definisi 3.2. [5] Misalkan $M$ merupakan matriks $n \times n$ dan akan diblok menjadi matriks $2 \times 2$.

$$
M=\left[\begin{array}{ll}
A & B \\
C & D
\end{array}\right]
$$

dimana $A$ adalah matriks $r \times r, D$ adalah matriks $n-r \times n-r$.

Jika A invertible maka komplemen Schur dari $A$ adalah $S_{A}=D-C A^{-1} B$.

Jika $D$ invertible maka komplemen Schur dari $D$ adalah $S_{D}=A-B D^{-1} C$. 
Teorema 3.3. [5] Jika $M=\left[\begin{array}{ll}A & B \\ C & D\end{array}\right]$ dan A,D merupakan matriks kuadrat maka determinan dari matriks $M$ adalah

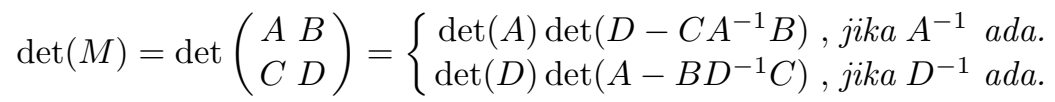

Teorema 3.4. [4] Misal $M$ adalah matriks $2 n \times 2 n$ dipartisi menjadi matriks blok $A, B, C$ dan $D$ yang berukuran $n \times n$, yaitu $M=\left[\begin{array}{ll}A & B \\ C & D\end{array}\right]$. Asumsikan $A, B, C, D$ komutatif berpasangan, dan $D$ invertible atau $A$ invertible maka

$$
|M|=|A D-B C| \text {. }
$$

\section{Bukti.}

1. Untuk D invertible, akan dibuktikan $|M|=|A D-B C|$.

Karena D memiliki invers maka berdasarkan Teorema 3.3, Teorema 2.8, dan Definisi 2.6 diperoleh

$$
\begin{aligned}
|M| & =|D| \cdot\left|A-B D^{-1} C\right| \\
& =\left|A D-B D^{-1} C D\right| . \\
& =\left|A D-B D^{-1} D C\right| \\
& =|A D-B I C| \\
& =|A D-B C| .
\end{aligned}
$$

Dengan demikian terbukti bahwa $|M|=|A D-B C|$.

2. Untuk A invertible, akan dibuktikan $|M|=|A D-B C|$.

$\operatorname{Mat}_{n}(C)$ adalah himpunan semua matriks kompleks berukuran $n \times n$ pada operasi penjumlahan dan perkalian.

Misalkan $D(M)$ adalah determinan dari matriks M yang dipandang sebagai matriks $k \times k$ dengan entri dalam $\operatorname{Mat}_{n}(C)$, dan $|M|$ adalah determinan matriks $M$ yang entrinya berada dalam $\operatorname{Mat}_{k n}(C)$.

Teorema 3.5. [4] Misalkan

$$
M=\left[\begin{array}{cccc}
A_{11} & A_{12} & \cdots & A_{1 k} \\
A_{21} & A_{22} & \cdots & A_{2 k} \\
\vdots & \vdots & \ddots & \vdots \\
A_{k 1} & A_{k 2} & \cdots & A_{k k}
\end{array}\right],
$$

yang elemen-elemen $A_{i j}$ dalam $\operatorname{Mat}_{n}(C)$ komutatif berpasangan. Maka berlaku

$$
|M|=|D(M)|=\left|\sum_{\pi \in S_{k}} s g(\pi) A_{1 \pi(1)} A_{2 \pi(2)} A_{3 \pi(3)} \cdots A_{k \pi(k)}\right| .
$$

Bukti. Dengan menggunakan Prinsip Induksi Matematika akan dibuktikan berlaku

$$
|M|=|D(M)|=\left|\sum_{\pi \in S_{k}} s g(\pi) A_{1 \pi(1)} A_{2 \pi(2)} A_{3 \pi(3)} \cdots A_{k \pi(k)}\right| .
$$


(1) Akan ditunjukkan untuk $k=1$ benar.

Karena $M=\left[A_{11}\right]$, maka

$|M|=\left|A_{11}\right|=\left|s g(\pi) A_{1 \pi_{1}}\right|$. Jadi untuk $k=1$ benar.

(2) Asumsikan untuk $k=r-1$ benar.

Berarti jika $M=\left[\begin{array}{cccc}A_{11} & A_{12} & \cdots & A_{1(r-1)} \\ A_{21} & A_{22} & \cdots & A_{2(r-1)} \\ \vdots & \vdots & \ddots & \vdots \\ A_{(r-1) 1} & A_{(r-1) 2} & \cdots & A_{(r-1)(r-1)}\end{array}\right]$ maka

$|M|=|D(M)|=\left|\sum_{\pi \in S_{r-1}} s g(\pi) A_{1 \pi(1)} A_{2 \pi(2)} A_{3 \pi(3)} \cdots A_{r-1 \pi(r-1)}\right|$.

(3) Akan ditunjukkan untuk $k=r$ benar.

Berarti $M=\left[\begin{array}{cccc}A_{11} & A_{12} & \cdots & A_{1 r} \\ A_{21} & A_{22} & \cdots & A_{2 r} \\ \vdots & \vdots & \ddots & \vdots \\ A_{r 1} & A_{r 2} & \cdots & A_{r r}\end{array}\right]$,

selanjutnya dilakukan Operasi Baris Elementer pada matriks M.

sehingga diperoleh $\left[\begin{array}{cccc}A_{11} & A_{12} & \cdots & A_{1 r} \\ O & -A_{21} A_{12}+A_{22} A_{11} & \cdots & -A_{21} A_{1 r}+A_{2 r} A_{11} \\ \vdots & \vdots & \ddots & \vdots \\ O & -A_{r 1} A_{12}+A_{r 2} A_{11} & \cdots & -A_{r 1} A_{1 r}+A_{r r} A_{11}\end{array}\right]=M^{*}$.

Partisi $M^{*}$ dengan memasukkan garis horizontal antara baris 1 dan 2, dan memasukkan garis vertikal pada kolom 1 dan 2. Sehingga diperoleh

$$
\begin{aligned}
M^{*} & =\left[\begin{array}{c|ccc}
A_{11} & A_{12} & \cdots & A_{1 r} \\
\hline O & -A_{21} A_{12}+A_{22} A_{11} & \cdots & -A_{21} A_{1 r}+A_{2 r} A_{11} \\
\vdots & \vdots & \ddots & \vdots \\
O & -A_{r 1} A_{12}+A_{r 2} A_{11} & \cdots & -A_{r 1} A_{1 r}+A_{r r} A_{11}
\end{array}\right] \\
& =\left[\begin{array}{cc}
A_{11} & * \\
O & N
\end{array}\right]
\end{aligned}
$$

Selanjutnya matriks $M^{*}$ akan difaktorisasikan kedalam bentuk perkalian berikut:

$$
M^{*}=\left[\begin{array}{cccc}
I & O & \cdots & O \\
-A_{21} & I & \cdots & O \\
\vdots & \vdots & \ddots & \vdots \\
-A_{r 1} & O & \cdots & I
\end{array}\right]\left[\begin{array}{cccc}
I & O & \cdots & O \\
O & A_{11} & \cdots & O \\
\vdots & \vdots & \ddots & \vdots \\
O & O & \cdots & A_{11}
\end{array}\right] M
$$

Berdasarkan persamaan (3.4) dan (3.5) diperoleh persamaan berikut:

$$
\left[\begin{array}{cccc}
I & O & \cdots & O \\
-A_{21} & I & \cdots & O \\
\vdots & \vdots & \ddots & \vdots \\
-A_{r 1} & O & \cdots & I
\end{array}\right]\left[\begin{array}{cccc}
I & O & \cdots & O \\
O & A_{11} & \cdots & O \\
\vdots & \vdots & \ddots & \vdots \\
O & O & \cdots & A_{11}
\end{array}\right] M=\left[\begin{array}{cc}
A_{11} & * \\
O & N
\end{array}\right]
$$

dimana $\mathrm{N}$ adalah matriks $(r-1) \times(r-1)$. Masing-masing matriks tersebut dinotasikan kedalam simbol yang ditulis sebagai 


$$
P Q M=R .
$$

Berdasarkan Teorema 2.8 dan Proposisi 3.1 diperoleh

$$
D(P Q M)=D(P) D(Q) D(M)=A_{11}^{r-1} D(M) \text { dan } D(R)=A_{11} D(N) .
$$

Akibatnya diperoleh

$$
A_{11}^{r-1} D(M)=A_{11} D(N) .
$$

Karena $r-1$ benar, maka pada matriks $N$ berlaku

$$
|D(N)|=|N| \text {. }
$$

Dengan demikian diperoleh

$$
\begin{aligned}
\left|A_{11}\right|^{r-1}|D(M)| & =\left|A_{11}\right||D(N)| \\
& =\left|A_{11} \| N\right| \\
& =|R| \\
& =|P\|Q\| M| \\
& =\left|A_{11}\right|^{r-1}|M| .
\end{aligned}
$$

Sehingga ketika $\left|A_{11}\right| \neq 0$ dapat dibagi kedua sisi dengan $\left|A_{11}\right|^{r-1}$. Oleh karena itu terbukti bahwa

$$
|M|=|D(M)|=\left|\sum_{\pi \in S_{r}} s g(\pi) A_{1 \pi(1)} A_{2 \pi(2)} A_{3 \pi(3)} \cdots A_{r \pi(r)}\right| .
$$

Karena $k=r$ maka terbukti benar

$$
|M|=|D(M)|=\left|\sum_{\pi \in S_{k}} s g(\pi) A_{1 \pi(1)} A_{2 \pi(2)} A_{3 \pi(3)} \cdots A_{k \pi(k)}\right| .
$$

\section{Kesimpulan}

Berdasarkan pembahasan dalam penelitian ini, dapat ditarik kesimpulan yaitu:

(1) Untuk $M=\left[\begin{array}{ll}A & B \\ O & D\end{array}\right]$, dimana $A, D$ adalah matriks bujur sangkar dan $O$ adalah matriks nol, berlaku:

$$
\operatorname{det}(M)=\operatorname{det}(A) \operatorname{det}(D)
$$

(2) Untuk $M=\left[\begin{array}{ll}A & B \\ C & D\end{array}\right]$, dengan $A, B, C$ dan $D$ adalah matriks berukuran $n \times n$ yang komutatif berpasangan, berlaku:

$$
|M|=|A D-B C| \text {. }
$$

(3) Untuk $M=\left[\begin{array}{cccc}A_{11} & A_{12} & \cdots & A_{1 k} \\ A_{21} & A_{22} & \cdots & A_{2 k} \\ \vdots & \vdots & \ddots & \vdots \\ A_{k 1} & A_{k 2} & \cdots & A_{k k}\end{array}\right]$,

yang elemen-elemen $A_{i j}$ dalam $\operatorname{Mat}_{n}(C)$ komutatif berpasangan, berlaku

$$
|M|=|D(M)|=\left|\sum_{\pi \in S_{k}} s g(\pi) A_{1 \pi(1)} A_{2 \pi(2)} A_{3 \pi(3)} \cdots A_{k \pi(k)}\right| .
$$




\section{Daftar Pustaka}

[1] Anton, H dan Chris. R. 2005. Elementary Linear Algebra. New York: John Wiley dan Sons.

[2] Gantmacher, F. R. 1960. The Theory of Matrices. New York: Chelsea Publishing Company.

[3] Jacob, B. 1990. Linear Algebra. New York: W. H Freeman and Company.

[4] Kovacs, I. Daniel S. S dan Susan G. W . 1999. Determinants of Block Matrices and Schur's Formula. The American Mathematical Monthly, vol. 106, No. 10, pp.950 - 952: Mathematical Assosiation of America.

[5] Meyer, C. D. 2000. Matrix Analysis and Applied Linear Algebra. Siam: Philadelphia.

[6] Rosen, K. H. 2012. Discrete Mathematics and Its Applications. New York: The McGraw-Hill Companies, Inc. 